\title{
Transformational Grammar and the Case of an Ndebele Speaking Aphasic
}

\author{
A. Traill \\ Department of Linguistics, University of the Witwatersrand
}

\section{Introduction}

There is a refrain running through much of current linguistic theorizing which says that language is rule-governed behaviour. If I am not mistaken there is an uneasiness running through much of Psychology and Speech Therapy which is based on the feeling that this linguistic view of language is somehow of great relevance to the understanding of normal and abnormal verbal behaviour but just what this relevance is, is not at all clear. This state of affairs is understandable if one bears in mind the following facts: firstly, Linguistics is not a unified discipline. Its practitioners agree that what they are doing is studying the structure of human language, but beyond this there is little agreement as to what this structure looks like, whether it is universal and, very importantly, how one should formalize it. Secondly, linguists study normal language and furthermore their descriptions are descriptions of langue in Saussure's sense or competence in Chomsky's sense. That is to say linguists qua linguists have nothing to say about how language is used (parole, performance) in listening, reading or speaking and writing, let alone describing the effects pathologies can have on these normal performances. All this is not to say that Linguistics has had no influence in Psychology or Speech Therapy. One finds phonemes, morphemes and syntax cropping up in both these fields and in a number of instances, more than lip service is paid to these concepts. It is no doubt due to the influence of men like $R$. Jakobson that we find linguistic concepts circulating amongst aphasiologists (cf. Jakobson 1964) and those concerned with language acquisition (cf. Jakobson 1968), although one suspects that his influence should have been greater than it has been.

Quite recently, the so-called Chomskyan revolution in linguistics has had repercussions in related fields, giving new direction to the interdisciplinary field of Psycholinguistics (for a summary of research see Fodor, Bever and Garrett 1968) and has given birth to what D. McNeill terms Developmental Psycholinguistics (examples of this new approach to the acquisition of language can be found in McNeill, 1966, Bellugi and Brown, 1964, Menyuk, 1969). Chomsky has stated on more than one occasion that linguistic theory is a psychological theory to the extent that it attempts to provide a formalization of the intuitive linguistic knowledge (competence) of the native speaker of a human language and 
it is therefore not surpising to find Linguistics having an impact on other disciplines. There is to my knowledge only one published attempt to apply the new theory literally to the field of language disorders and this is Marshall and Newcombe's study of syntactic and semantic errors in paralexia (Marshall and Newcombe, 1966). Had the new theory stood still for long enough we would doubtless have had more examples of its application to the analysis of language disturbances in adults and children.

The rationale underlying this recent work in psycholinguistics is as follows: the grammar of a language is a formalization of the intuitive linguistic knowledge which a native speaker of a language internalizes in the course of learning his language and which constrains what is to count as acceptable performance in the language. The formalization is effected by various types of rules operating at various levels of representation: the phonological level, the syntactic level and the semantic level. The theory provides a mechanism for mapping one level of representation onto another, but not in any order: the syntactic level is regarded as central in Standard Transformational Theory and the syntactic representations are mapped onto semantic and phonological representations. The theory thus provides an integrated formalization of the informal observation that sentences in a language have pronunciation (phonological representation), meaning (semantic representation) and syntax (syntactic representation). Furthermore, the pairings of meanings and pronunciations (sounds) with syntax mediating, is over an infinite domain. That is to say, one of the facts about native speaker competence which is accounted for in the theory, is that a native speaker of a language is, in principle, able to comprehend and produce an infinite number of sentences including typically ones which are wholly novel. Put slightly differently, the grammar of a language provides a definition of the infinite set of grammatical sentences in that language.

What the psycholinguists have done, is to regard this theory as a source for formulating hypotheses about linguistic performance. They have, in other words, attempted to predict psychological complexity from complexity in a grammar. If a certain sentence has $n$ rules in its derivation in the grammar, and another sentence as $n+2$ rules in its derivation, then the expectation is that the latter sentence will be more difficult to perform (recall, respond to etc.). Early experiments had encouraging results, later ones were positively discouraging (see Fodor et al op. cit. and Schlesinger, 1966). Marshall and Newcombe's analysis showed that aspects of the transformational grammar of the paralexic they studied had been interfered with through a lesion caused by a bullet. This suggested quite startling confirmation for the psychological reality of linguistic constructs and came from an unexpected source; clearly, the transformational grammar of English which they used was not written with the aim of explaining linguistic disturbances.

Nevertheless, there remains something of a paradox in this work. It is that grammars formalize competence; they do not provide a model 
of performance. Yet in some cases they successfully predict performance complexity while failing in others. An attempt to get round this was made by Fodor and Garrett (Fodor and Garrett 1966) by claiming that the relationship between competence and performance is not, as was previously thought, a direct one; rather it is abstract. But this move is quite unhelpful and seems to me to provide no useful exit from the dilemma. We are merely left with some experiments that worked and others that didn't. One wonders why any experiments worked at all.

It is in the context of the foregoing that I would like to discuss the aphasia of W.N., a mother-tongue speaker of Ndebele.. a south-eastern Bantu language of the Nguni group, spoken in Southern Rhodesia, and except for minor differences the same as Zulu. My purpose in exploring his linguistic impairment in transformational grammatical terms is not in order to make a direct contribution to the controversy over the relationship between competence and performance, although it is clear that the results unavoidably bear on this; instead, I am primarily interested in recording and analysing the case of an extraordinarily specific impairment in a language quite unlike English in its superficial aspects.

\section{History of the Case}

W.N., an adult male aged 52, was referred to the University of the Witwatersrand's Department of Speech and Hearing Therapy from Baragwanath Hospital, Johannesburg, where he had undergone surgery for a head wound on the left side of his head ${ }^{1}$ sustained during an assault. On the Schuell test he was diagnosed as suffering from severe expressive aphasia. ${ }^{2}$ This diagnosis is, of course, based on his performance in English, but it is supported by my data consisting only of his performance in. Ndebele. He is currently undergoing therapy in English and, at the time my data were collected, he had had a certain amount of therapy, also in English.

\section{The Data}

The data on which the analysis is based were collected during four half-hour interviews over two successive weeks. Each interview was taped and transcribed immediately thereafter. This enabled one to supply any contextual clues necessary for interpretation'.

It should be pointed out that the two hours of interviewing time yielded a small number of utterances (105), which is, of course, understandable in view of W.N.'s expressive difficulty. However, since his performance did not vary in quality from one interview to the next, and since, as will become clear later, I was not concerned to analyse his impairment with respect to the whole language, but was concerned rather with one aspect of Ndebele structure, I found the sample quite adequate for my purposes. In fact, the structural aspect of Ndebele 
in which $I$ was interested, is so pervasive a feature in that language (or any Bantu language) that it is unusual to find a sentence not manifesting this feature: This meant that nearly all W.N.'s utterances exemplified the difficulties he has with this feature.

\section{Zulu-Ndebele Concordial Structure}

While there are no authoritative sketches of Zulu syntax in transformational generative (T.G.) terms, the theory is for the most part explicit on the principles involved in accounting for concordial structure. This does not mean that the theory dictates the solution in its ultimate details, but that it provides a set of constraints on the general form of the solution. Put differently, it tells you where in the grammar various facts should be formalized.

Taking Standard T. G. (the attribute "standard" has been introduced in order to distinguish earlier versions of the theory from recently proposed alternate models; Chomsky, 1965, is regarded as a statement of Standard T.G.) as the model for the following discussion, the components of a grammar and their inter-relationships can be represented as in Figure 1 (adapted from Fodor et al 1968).

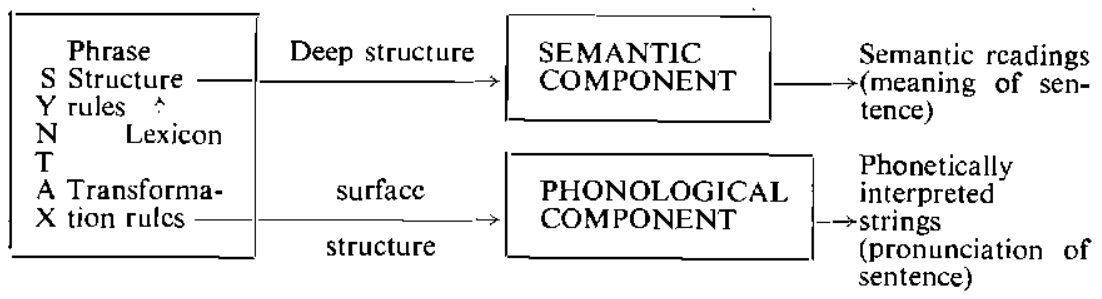

Fig. 1

This grammar provides a specification of the meaning (semantic component) and pronunciation (phonological component) for each of the infinite number of grammatical strings enumerated by the syntactic component. The latter component consists of two sub-components, a base, in which phrase structure rules formalize those syntactic aspects of a sentence which affect the meaning of the sentence (categorial membership, e.g. $\mathbf{x}$ is a noun, the $\mathbf{x}$ is a noun phrase, and relational concepts, e.g. $\mathbf{x}$ is the subject of the sentence), and a transformational component consisting of rules which produce surface structures through operations of deletion, substitution and adjunction on the strings provided by the base component. These transformational rules do not affect the meaning of the sentence; they provide the "syntactic trappings" (Langacker 1968) of a language such as affixes, order of constituents, etc. Once these rules have applied to produce a surface structure, the phonological component assigns a pronunciation to this structure. The lexicon consists of an unordered list of the lexical items in the language which are specified in terms of their phonological shape, their syntactic potential and their meaning. After the base sub-com- 
ponent has operated to produce an abstract syntactic form, lexical items are substituted from the lexicon at designated places. It is the base structure with its lexical items which is the input to the semantic component.

Turning now to Zulu, one finds a syntactic phenomenon which has traditionally been called the concordial system. This system can be characterized briefly and informally as a syntactic device which marks explicitly all those constituents in the sentence which are "governed by" a noun. Furthermore, these explicit marks are phonologically "similar to" the prefix of the noun, whence the term alliterative concords in which "concord" refers to the syntactic relationship, and "alliterative" to the phonological one. (1)-(4) below illustrate this.

I. u.mu.ntu, u.ya.hamb.a the person

$$
\text { is going }
$$

2. i.si.tsha the dish

$$
\text { si.w.ile }
$$

$$
\text { has fallen }
$$

3. a.ma.hhashi

$$
\text { a.mi a.ma.khulu }
$$

ma.hle horses

my big

are beautiful

( $\mathrm{my}$ big horses are beautiful)

$$
\begin{array}{ccc}
\text { 4. a.ba.ntwana } & \text { b.a.mi } & \text { a.ba.khulu } \\
\text { children } & \text { my } & \text { big } \\
\text { (my big children are beautiful) }
\end{array}
$$

\author{
ba.hle \\ are beautiful
}

(Full stops signify morpheme boundaries.)

Just what is meant by the term "alliterative concord" should be clear from these examples. As the governing noun changes, so do the prefixes on governed forms: possessives, adjectives, verbs, etc. Traditional descriptions of this phenomenon have in the main simply listed the various noun prefixes and also the prefixes which appear on the governed forms. Thus one finds lists of numbered noun prefixes, possessive prefixes, adjectival prefixes, verb prefixes, etc. and a statement to the effect that possessives, etc. agree in number and class with the noun that governs them. Thus, if the governing noun is Class I, then governed forms appear with the appropriate Class I alliterative concords.

In terms of figure 1 , the account of this phenomenon is radically different. For example, in order to explain why concords appear where they do in sentences, we need to specify a set of syntactic conditions which formalize the notion of "governed constituent". These conditions are specified by the phrase structure rules of the base component. The explicit marking of the agreements is achieved through a transformational rule which marks governed forms with the class designation of the governing noun while at the same time capturing the alliterative aspect of the agreement by substituting the same phonological shape at appropriate positions in the sentence. In this treatment, therefore, concordial agreement is regarded as a "syntactic trapping" of Zulu. This follows from the fact that it is effected through transformational rules only.

Journal of the South African Logopedic Society, Vol. 17, No. 1: December 1970 
As illustration, consider the following highly simplified steps in the derivation of i.si.tsha si.w.ile (The dish has fallen)

1. Deep structure representation in terms of the phrase structure rules:

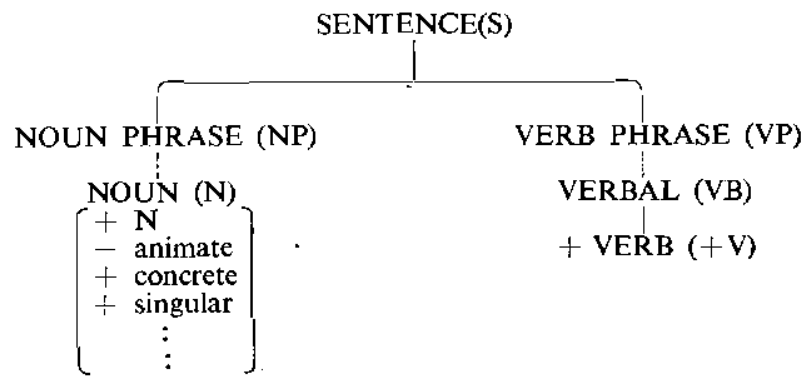

2. Lexical entry for i.si.tsha (dish) in the lexicon

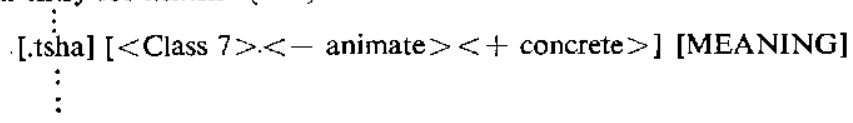

3. Lexical substitution in (1)

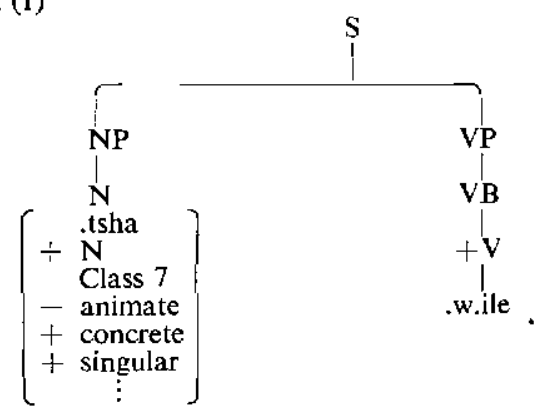

4. (3) is the input to the semantic component and has a meaning assigned to it.

5. (3) is also the input to the Transformational component which performs the following operations on the sentence:

5.1. T-agreement. This transformation copies specified features of the governing noun onto governed forms, in this case the verb.

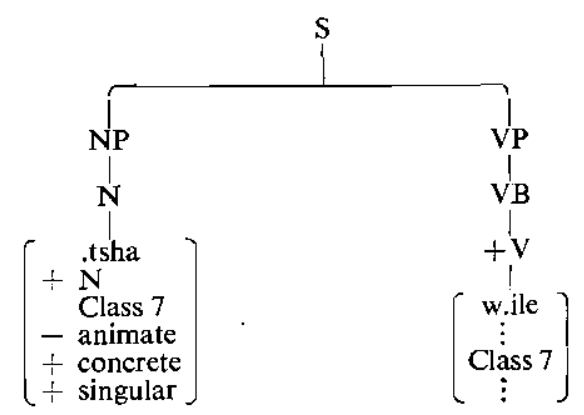

Tydskrif van die Suid-Afrikaanse Logopediese Vereniging, Vol. 17, Nr. I: Des. 1970 
5.2. T-class segmentalization. The effect of this transformation is to convert a representation of the form $X$ to $\langle+y\rangle \quad X$, in this case $\langle+y\rangle$ is the feature $\langle$ Class 7$\rangle$. $<+y><+y>$

The output of this rule is:

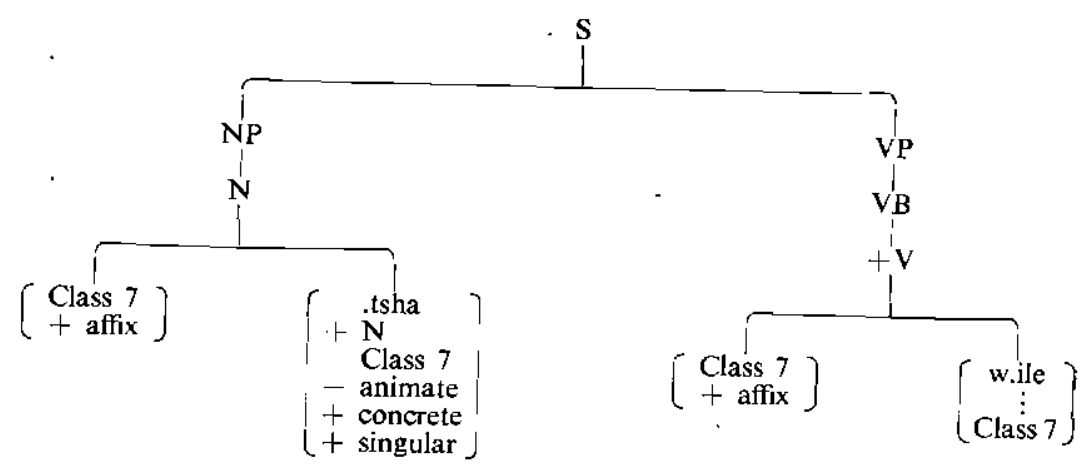

5.3. At this stage in the derivation a lexical pass which scans the sentence to determine whether any segment created by a transformational rule requires to be spelt out, will substitute the following lexical entry for each occurrence of $\left[\begin{array}{l}\text { Class } 7 \\ + \text { affix }\end{array}\right]$

[si.] $[<$ Class $7><+$ affix $><+$ singular $>$ ].

The effect of the lexical pass on the structure in $(5.2)$ is :

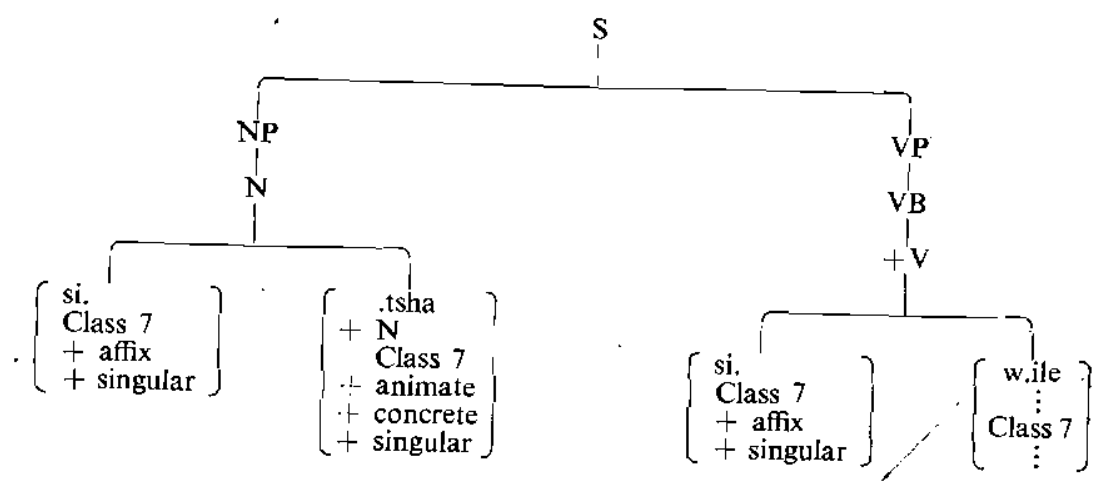

5.4. Prothetic vowel spelling. For our purposes, at this stage of the derivation there are no further syntactic (transformational) rules to be applied. The structure in (5.3) therefore represents the input to phonological rules of which prothetic vowel spelling is the one required at this stage. Its effect is to copy the vowel of the noun prefix before the consonant in the prefix. Thus si. $\rightarrow$ isi., or slightly more formally: si. $\rightarrow$ isi./ $-+N$, which says that si. becomes isi. in the context of a

Journal of the South African Logopedic Society, Vol. 17, No. 1: December 1970 
following noun. ${ }^{3}$ This completes the derivation, whose successive stages were :

(i) $\left[\begin{array}{c}\text { tsha } \\ \cdot \\ \cdot \\ \text { Class } 7\end{array}\right]$

w.ile (after lexical substitution in base)

(ii) $\left[\begin{array}{ll}\text { ttsha } \\ \text { Class } 7\end{array}\right] \quad\left[\begin{array}{l}\text { w.ile } \\ \text { Class } 7\end{array}\right] \quad$ (T-agreement)

(iii) Class 7 .tsha Class 7 .w.ile (Class segmentalization)

(iv) si.tsha si.w.ile (lexical pass)

(v) isi.tsha si.w.ile (prothetic vowel).

There are many complications facing anyone attempting to write rules which both simply and generally formalize all the facts of concordial agreement in a language like Zulu, and the above illustration is by no means supported by an explicit account of these rules. But whatever these rules look like ultimately, it seems clear that at least the steps above will be required. In the discussion of W.N.'s performance, I shall maintain an informal approach to these rules while at the same time believing that they are in general outline correct.

\section{The Structure of the Noun}

Consider the following examples of nouns produced by W.N., as single word responses to questions. When there is an error, the correct form appears in brackets.

1. i.hhashi horse

2. in.konyane calf

3. aba.ntu people

4. u.dokotela doctor

5. i.gwatsha rabbit (u.nogwatsha)

6. i.Zulu Zulu (isi.Zulu)

7. um.gwatsha rabbit (u.nogwatsha)

8. n.kunzi bull (in.kunzi)

9. ma.thambo bones (ama.thambo)

10. ba.twana children (aba.ntwana)

11. .ntwana child (um.ntwana)

12. .komo cow (in.komo)

13. .godi hole (um.godi)

14. .gwatsha rabbit (u.nogwatsha)

15. .bisi milk (ubisi)

(1)-(4) are all correct, both with regard to prefix and stem of the noun, (5)-(7) have correct stems and structurally perfectly good prefixes, except that they are the wrong prefixes for those stems. (8)-(10) have correct stems but only partially correct prefixes: each one lacks an obligatory initial vowel, as can be seen from an examination of the 
correct forms. (11)-(15) have correct stems but no prefixes at all. As can be seen from (5), (7) and (14), and (10) and (11), the same stem can appear with various prefix errors.

These errors are for the most part readily interpretable in terms of the description of the preceding section. What is of particular interest, however, is that if one bases an error classification solely on these examples, then one finds that it is not always possible to identify a unique locus for an error. That is to say, a particular error could be the result of a breakdown of one or another rule and it is not possible to decide which rule it is.

Consider, now, the following "explanations" of the errors. From the first category ((5)-(7)), (6) is, in terms of what has preceded, the best example to discuss. The noun isi.Zulu (the Zulu language) has the following derivation:
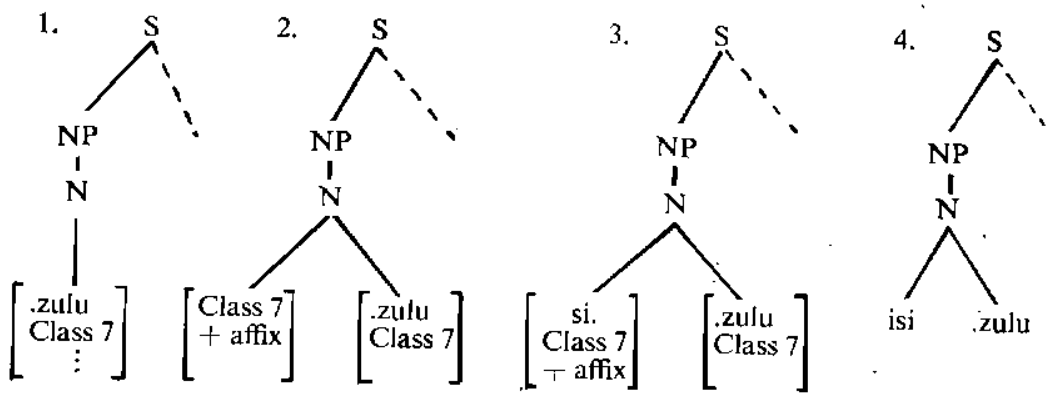

The form which was produced, $i . Z u l u$, is a noun in Zulu, but its class designation is "Class 5", and its meaning is "heaven" or "sky". Recall that in the lexicon a noun stem is specified as to pronunciation (P), class membership (C) and meaning (M). In this case, the pronunciation is correct, and the intended meaning was without doubt "Zulu language". Therefore, in the triple (P, C, M) the error must be in (C). Bearing in mind that the same stem can manifest different prefix errors, we could suggest that $(C)$ is unstable varying between $\langle$ Class 7$\rangle$ and $\langle$ Class 5$\rangle$ and presumably others. If it is substituted into the base with (C) as $<$ Class $5>$, the error could be explained.

But there is another explanation which locates the error, not in the lexical entry for the stem but in the lexical entry for the prefix, which has the general form: [pronunciation] [Class]. If we allow the specification for [class] to be unstable here, the error would be'equally well accounted for. Instead of steps (3)-(4) above, we would have $\left(3^{\prime}\right)-\left(5^{\prime}\right)$.

A third possibility is that the locus of error lies in the specification of the pronunciation of the prefix in the lexicon. Thus, instead of having [si.] [Class 7], [li] [Class 7] would occur.

Summarizing these three suggestions, the error could be located in (a) unstable (C) of the stem, (b) unstable (C) of the prefix, (c) wrong (P) of prefix. The only common feature these explanations possess is that they all locate the error in the lexicon and not in the syntax. 

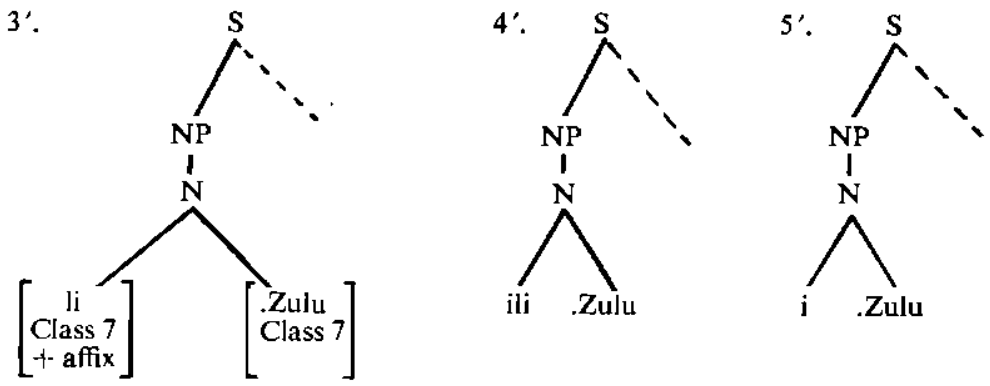

$\left(\left(5^{\prime}\right)\right.$ involves a rule not previously discussed).

Errors (8)-(10) are to be explained in terms of the failure to apply the transformation which segmentalizes the features $<$ def $>$ or $<$ indef $>$ on nouns in positive contexts. The rule of prothetic vowel spelling is therefore blocked: there is no formative to be spelled. It is worth noting that when W.N. does spell out this vowel, it is always correct. When he fails to do so, therefore, he is not failing at a superficial phonological level, but at a deeper syntactic one. The reader should consult footnote 3 for a slightly more detailed discussion of these facts.

(11)-(13) also have alternate explanations. Firstly (C) of the lexical entries for these stems could be missing which would mean that "Class Segmentalization" could not apply. Secondly, it could be suggested that the entries for the stems were perfect, that "Class Segmentalization" did apply, but there were no lexical entries for the prefixes. The effect of this would be that step (2) above would be reached in the derivation of these nouns, but on the failure of any lexical material being substituted for the prefix (there being no entries for the prefixes), the segment $[$ Class $x]$ would be deleted in accordance with the lexical seg. + affix

ment deletion convention (LSD) (Rosenbaum 1967). Thirdly, the error could result from conflicting (C) specifications on the stem and the prefix. Notice that [si.] substitutes in step (3) above just because both it and the segment preceding the noun are identically specified [Class 7.].

If the $(C)$ of [si.] [ If the (C) of [si.] was, say <Class $5>$, there would be conflict and no substitutions could take place, with the result that LSD would delete the segment preceding the noun, giving the forms in (11)-(15).

In the summary, the errors (11)-(15) could be attributed to (a) nonexistent (C) on stem, (b) non-existent lexical entry for prefixes, (c) conflicting (C)'s on stem and prefix. Again, all these suggestions locate the error in the lexicon.

The "diagnosis" at this stage is that all errors excepting (8)-(10) are to be traced to instabilities or misinformation in the lexicon. It is interesting to note that what is essentially an "agrammatism" in traditional terms is not being located in the syntactic component of the 
description at all but in the lexical sub-component. This in fact reveals a central feature of transformational grammars: it is that the pairings of meaning and sound involve long and complex chains of rules and dependencies such that a decision to represent linguistic information in a particular form and at a particular point in the description will have repercussions throughout the derivation of a sentence. It follows from this that in the case of a linguistic pathology located at a specific point in the description, we can expect to find repercussions throughout the system, and if we pursue the effect of the inadequate lexical entries for W.N.'s nouns and normal prefixes beyond the noun itself, we can expect to find far-reaching effects on other parts of sentence structure. Hopefully, this may enable us to fix more accurately the location of his particular breakdown.

\section{The Agreement Transformation}

In 5.1. the effect of T-agreement was informally sketched: specified features of the governing noun are copied onto governed forms. This rule captures the notion that certain forms in the sentence agree syntactically with certain nouns. It is only in a subsequent rule in which the agreement is lexically "spelled out" that we formalize the further notion that the syntactic agreement is phonologically alliterative. A point worth emphasizing, is that this set of rules embodies a dependency, namely that certain constituents depend for their correct surface shape on a governing noun's syntactic feature composition. Put differently, governed forms acquire their class prefixes; nouns have a class prefix as an inherent specification.

In the light of the preceding discussion of the structure of W.N.'s nouns, it should come as no surprise to learn that his T-agreement produces unaçceptable surface structures. In terms of the grammatical model, however, it is the details of these derivations which are of interest.

A most significant fact about the pattern of agreement errors, is that while there are a number of different types of error, they all reflect

\begin{tabular}{|c|c|c|c|}
\hline Noun Prefix & $\begin{array}{l}\text { Governed } \\
\text { Prefix }\end{array}$ & Example & Correct Form \\
\hline 1. Correct & $\begin{array}{l}\text { a. Correct } \\
\text { b. Incorrect } \\
\text { c. Zero }\end{array}$ & $\begin{array}{l}\text { u.nogwatsha u.hleli } \\
\text { i.hhashi u.lele } \\
\text { in.komo baleka }\end{array}$ & $\begin{array}{l}\text { i.hhashi li.lele } \\
\text { in.komo i.ya.baleka }\end{array}$ \\
\hline 2. Incorrect & $\begin{array}{l}\text { a. Incorrect } \\
\text { b. Zero }\end{array}$ & $\begin{array}{l}\text { i.Zulu i.nzima } \\
\text { ma.phoyisa dinga }\end{array}$ & $\begin{array}{l}\text { isi.zulu si.nzima } \\
\text { ama.phoyisa a.dinga }\end{array}$ \\
\hline 3. Zero & $\begin{array}{l}\text { a. Incorrect } \\
\text { b. Zero }\end{array}$ & $\begin{array}{l}\text { ntwana i.nye } \\
\text { not in data }\end{array}$ & um.ntwana mu.nye \\
\hline
\end{tabular}

Journal of the South African Logopedic Society, Vol. 17, No. 1: December 1970 
the dependency mentioned above. The facts are summarized in the table below.

There are no examples showing an incorrect or zero noun prefix matched with a correct governed prefix. This suggests very strongly that whatever else may be wrong with W.N.'s agreement rule, it always respects the dependency of governed forms on the governing noun; if the latter is inadequately or incorrectly specified, then the former will never show correct agreement.

Errors of the type (Ic) (2b) (and the hypothetical (3b)) in the above table can be explained in a number of ways. Firstly, T-agreement could have failed to copy the class feature onto a governed form, in which case the rule "Class Segmentalization" would fail to apply with the result that no lexical substitution could take place, giving no governed prefix. Secondly, it could not be held that T-agreement did apply, but Class Segmentalization did not, giving zero again. Thirdly, both T-agreement and T-Class Segmentalization could have applied, but the lexical substitution of a prefix failed to take place (this type of failure was discussed above for noun-structure) with the resultant deletion of the segment $\left[\begin{array}{c}\text { Class } x \\ + \text { affix }\end{array}\right]$ by the LSD convention.

What is clear from this discussion is that we are still no nearer establishing a unique locus for the errors. Exactly why one should search for a unique locus derives, I think, from the feeling one gets from examining the errors, that W.N.'s concordial system does not work and one suspects intuitively that this disruption should be traceable to a unitary process in the grammar, rather than have it distributed over diverse rules. Also, one can not shake the feeling that a unitary explanation will be a more parsimonious one, although $I$ have no idea whatever about the relationship between Occam's razor and an assailant's knife when the dissolution of language is being discussed. Fortunately, there are a few crucial observations which suggest very strongly the interpretation that should be adopted.

To say that W.N.'s concordial system does not work is misleading, for if one takes a careful look at what it is that is not correctly represented in his speech, one sees that there is evidence of a system of concordial prefixes but this system is inadequate with respect to normal Zulu syntax because W.N.'s system is not alliterative. ${ }^{4}$ In other words, his system certainly allows for "agreements" (concord) between constituents; it even allows for these agreements to be pronounced in the form of prefixes. But, it does not require that the prefixes be alliterative. This is a crucial observation for we can now ask just where the notion "alliterative" is formalized in the grammar, and if this is done in one place, we shall have the locus of W.N.'s deficiency. A further observation which supports the contention that a system of agreement is in operation comes from the fact already noted that W.N. preserves the dependency of governed forms on a governing noun to the extent that we find no errors of the type incorrect governing noun prefix + correct governed 
prefix. This means that although it appears that the errors on nouns arise independently of the errors on governed forms, this is not in fact so; there is not complete freedom of choice for noun prefixes and governed prefixes. If this is so, a plausible suggestion would be that $\mathrm{T}$-agreement always operates thus bringing governed forms into agreement with the governing noun. At a later stage the alliterative aspect of the agreement fails to materialize.

The notion of alliteration is in fact uniquely located in the grammar: all concordial prefixes are alliterative simply because there is only one phonological entry for each class prefix. This means that the same phonological shape is substituted for each $[$ Class $x]$ segment created by T-class segmentalization. We need, therefore, recognize only one inadequacy in W.N.'s grammar in order to account for lack of alliteration and that is in the (C) specification for prefixes in the lexicon. The simplest solution would be to claim that he has no $(C)$ at all but a list of entries for the prefixes specified as (P) $[<+$ affix $>< \pm$ singular $>$ ]. The stage just prior to the substitution of an arbitrary prefix would then be

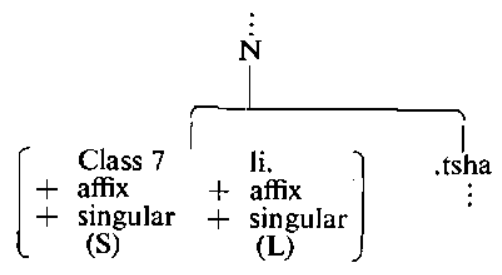

$(S)$ is the set of syntactic features and $(\mathrm{L})$ the set of lexical features. The two sets are non-distinct (as opposed to being idenical (cf. Chomsky . 1965 , p. 181)) thus allowing the substitution of $\langle$ li. $\rangle$. This suggestion permits the substitution of any lexical entry specified $\left[\begin{array}{l}+ \text { affix } \\ + \text { singular }\end{array}\right]$

to be substituted for any syntactic segment

$\left[\begin{array}{l}\text { Class } x \\ + \text { affix } \\ + \text { singular }\end{array}\right]$ and any lexical entry specified $\left[\begin{array}{l}+ \text { affix } \\ - \text { singular }\end{array}\right]$

for any syntactic segment $\left[\begin{array}{l}\text { Class } x \\ + \text { affix } \\ - \text { singular }\end{array}\right]$

This may be too powerful a rule since not all the possibilities it allows are found in the data. Nevertheless, a sufficiently large number of the possibilities are attested for one to believe that the rule is correct in principle. In any event its power could quite easily be restricted. ${ }^{5}$

Two further comments are required in order to complete the picture. Firstly, under the present interpretation of W.N.'s deficiency, a completely successful marking of alliterative concordial agreement (1 (a) 
in the table above) must be regarded as quite fortuitous. We are, therefore, not allowing for the possibility of the correct operation of the process being distorted only at a later stage, shall we say during the motor-phase of production of a sentence. We have, in effect, formalized his error in the grammar and are thus making the significant claim that his competence is impaired rather than claiming his error is due to an inadequacy in his performance mechanism. Indeed, given that we know next to nothing about performance, it seems we have no alternative. We shall see later when examining W.N.'s performance on comprehension that this conclusion is at best a nuisance and at worst of dubious correctness.

The second comment concerns the question of how it is that one finds a certain prefix appearing on the noun and a different one on the governed form. The explanation is that the convention governing lexical substitution does not allow more than one substitution at a time. Presumably any segment $\left[\begin{array}{c}\text { class X } \\ + \text { affix }\end{array}\right]$ could be the first to undergo

lexical substitution, but, presuming it is the noun prefix which is first affected, then it will be the case that the verb concord will be affected in a subsequent substitution. Clearly, in the case of W.N.'s lexicon, the result of the second substitution need not be the same as the first.

The explanation adopted so far accounts adequately for all types of error except those where no prefix materializes on either nouns or governed forms. All one needs in order to account for this category is to allow for the failure of lexical substitution of affixes; LSD does the rest. In case this proposal seems extremely ad hoc, let me point out that its effect would be to produce "telegraphese", and there is ample evidence of the phenomenon in the data.

\section{Testing Receptive Control of Concordial Structure}

During interviews, W.N. showed no evidence at all of comprehension difficulties. But, owing to the extensiveness of concordial breakdown in speaking, coupled with the fact that concords are "syntactic trappings", and, therefore, do not contribute meaning as such, I felt it necessary to determine the extent to which concords were preserved in comprehension. An extremely simple but revealing test indicated quite clearly that W.N. was able to utilize the anaphoric properties of concords in order to arrive at the underlying meaning of a proposition.

The test was based on the fact that, whereas in English pronominal forms such as "the one who is lying down" are multiply ambiguous (who or what does "the one" refer to?), in Zulu one is able to narrow down the ambiguity of reference to a particular noun class. For example, the forms olulele, olele, elilele, elele, are all glossed in English as "the one who/which is lying down", but in Zulu the first is "the Class 11 which is lying down", the second "the Class 1 or $3 \ldots$..", 
the third "the Class $5 \ldots$ " and the fourth "the Class $9 \ldots$. W.N. was presented with various toys, the nouns corresponding to which fell into various classes. He was then asked to point to the one (ones) which was (were) lying down, following the man, eating the food, etc. A typical situation would be as follows: a duck (lying down), a cow (lying down) and a tortoise (standing). He would be asked: khomba elilele (point to the one which is lying down). The only correct response in this case is to point to the duck. If he had been asked: khomba elele, only the cow would qualify. He performed successfully on all these tests.

Notice what he has to do in order to give the appropriate response. Firstly he has to identify the class designation of the pronominal prefix, i.e. as Class 5 or Class 11 or Class 1, etc. Since this is an acquired prefix (governed form), he has secondly to identify an object in the situation whose noun is a Class $5,11,1$, etc. noun. Let us say he has to "recover" the deleted noun which determined the form of the alliterative concord. Having done this, he is then able to respond correctly. It cannot be argued that the extralinguistic context facilitates his response in such a test since this context is ambiguous with respect to objects lying down. Successful performance here demands perfect control of the concordial "signals". This could be phrased differently as the reverse application of the transformations effecting agreement:

The problem which now arises is that we have shown W.N.'s concordial processes to be intact in reception, but to be impaired in production. He thus shows perfect competence on the one hand and imperfect competence on the other. ${ }^{6}$ Yet competence in the technical sense is monolithic; it is neutral with respect to comprehension or production. How is this conceptual tangle to be resolved?

There are three approaches to this issue. Firstly, and I believe this is what a lot of linguists would claim, the tangle is the result of an illegitimate exercise in applied linguistics: linguistic theory was not intended for bizarre forms of language. Secondly, one could adopt the view of Weigl and Bierwisch (Weigl and Bierwisch 1970) that all aphasia involves a breakdown in the performance mechanism; that the competence remains intact but is blocked. Thirdly, along with Whitaker (Whitaker, 1969) one could argue that both competence and performance may be affected in aphasia and, in the case under discussion, the performance mechanism concerned with the speaking modality has broken down. The distinction between the last two views is that in the latter, impaired competence is countenanced, whereas in the former it is not. If W.N. had shown a defect in both the listening and speaking modalities Whitaker would, in the absence of evidence to the contrary, be willing to diagnose his competence as being impaired.

Whitaker discusses the above three positions extensively and, rather than reiterate his lengthy arguments' here, I should merely like to note that the position he adopts must be seen in the context of his model for the representation of language in the brain and his views on the 
relevance of data from linguistic pathologies for assessing the explanatory power of a linguistic theory. But whether we adopt Weigl and Bierwisch's or Whitaker's diagnosis in the present case, we are left with the same claim: W.N.'s deficit is a performance one; in Whitaker's terms is would be attributed to the imperfect workings of the synthesizing "tracking" strategy in the mechanism for the speaking modality. Exactly what this strategy is, and just how it would operate in the case of Zulu concordial structure is something about which we can say nothing. This is, to say the least, an uncomfortable conclusion to arrive at, but in the context of current views on competence and performance it seems to be unavoidable.

What then of the foregoing attempt to "formalise" W.N.'s nonalliterative concordial "system"? The positions I have just reviewed would doubtless regard this as wrong, and certainly if one accepts that competence is represented in the brain, that it is distinct from performance and, if one recalls the asymmetry between the listening and speaking modalities of W.N.'s performance, one is forced to agree with them. In order to legitimize the formalization I have attempted, it would have to be demonstrated that W:N.'s deficit at least cuts across all modalities, thus suggesting that competence has been affected (if I understand Whitaker correctly, this would be his view) ${ }^{7}$. This follows from the assumption that competence is modality free. But this position reflects only a necessary condition for positing a competence deficit; it is not a sufficient condition simply because one cannot be sure, given an impairment in all modalities, that this is not perhaps a performance problem of a global nature. The global aphasia mentioned by Weigl and Bierwisch illustrates the undecidability of the problem: is this a total breakdown of the performance mechanism for all modalities with competence remaining intact; or is it a total destruction of competence with the consequence that the application of the performance mechanism is vacuous? (I wonder if the latter is a genuine possibility. If the domain of operation of the performance mechanism (competence) is removed, is there any reason why this mechanism should continue to exist?) Owing to the general limitations on our knowledge at present and on mine in particular, I do not propose to explore these questions any further. I should like, however, to make one observation concerning the type of information which would be necessary for the operation of Whitaker's "tracking" strategy for that aspect of the speaking modality in Zulu which involves making concordial agreement.

If one accepts that W.N. suffers from a performance defect, then an examination of his errors in S.T.G. terms shows quite clearly that we need to recognize specifically syntactic "tracking" strategies which presumably must operate in real time prior to and independently of phonological "tracking" strategies. The reason for maintaining this is that the syntactic tracking strategy which synthesizes the sentence at one level must, as the examples show, break down whenever a "seg- 
ment" categorized as $\left[\begin{array}{c}+ \text { Affix } \\ \text { Class X }\end{array}\right]$ is "processed". W.N.'s difficulty cannot be relegated solely to inadequate operation of pronouncing strategies because his errors hinge on syntactic information. Put differently, if by "performing a pronunciation synthesizing strategy" we mean the activation of a path through neuro-motor, myomotor and articulatory stages (Liberman et al, 1967), it is not at all clear how a syntactic specification is carried through to these stages causing (?) a breakdown in operation. Surely the proper functioning of this stage of production cannot be made to depend on syntactic information. Put still differently, if an element [A B A B] is constantly (and variously) "mispronounced" in the first two 'phonemes' $\mathrm{AB}$, and if $\mathrm{AB}$ also appears in other positions, but is never mispronounced there and, further, we discover that the first $\mathrm{AB}$ is in fact $\mathrm{AB}]$ whereas the second is not, then

$$
\left[\begin{array}{c}
\text { Class X } \\
+ \text { Affix }
\end{array}\right]
$$

obviously it is not just $A B$ that is "difficult to pronounce"; rather it is $\mathrm{AB}$ when it is syntactically categorized as a Class Affix. An actual example is (abantu) babaleka ((the people) run away). W.N.'s performance interferes with the first $b a$, not the second. If performance strategies are, as is suggested above, sensitive to syntactic information presented in the competence formalization, it follows that this information must be duplicated exactly in the two components, once in competence and once in the tracking strategies. While I would hesitate to suggest that the brain hasn't enough room to accommodate this sort of duplication, I would venture no more than that it is surprisingly wasteful and is a direct consequence of claiming that competence has neurological correlates separate from performance.

\section{Summary}

In summary, there are three points to mention: Firstly, the attempt to analyse W.N.'s linguistic pathology in terms of a transformational generative grammar raised the problem of localizing the source of the defect (notice that the mere fact of being able to offer any localization in this grammar is an interesting result). Secondly, the approach adopted, lead to the contradictory assertion that W.N.'s competence was impaired in production but not in comprehension. Thirdly, this raised the vexing question of the relationship between' competence and performance and highlighted our ignorance of the operation of the latter.

\section{References}

Bellugi, U. and Brown, R. (1964) (Eds.); The Acquisition of Language. Monographs of the Society for Research in Child Development, 29.

Chomsky, N. (1965): Aspects of the Theory of Syntax. Cambridge: M.I.T. Press.

Journal of the South African Logopedic Society, Vol. 17, No. 1: December 1970 
Fodor, J. A., Bever, T. G. and Garrett, M. (1968): The Development of Psychological Models for Specch Recognition. Report No. ESD-TR-67-633 to the U.S.A.F. Available from the Clearing House for Federal, Scientific and Technical Information.

Fodor, J. A. and Garrett, M. (1966): Some reflections on competence and performance in J. Lyons and R. Wales (Eds.), Psycholinguistic Papers, Edinburgh : E.U.P.

Jakobson, R. (1964): Towards a linguistic typology of aphasic impairments. In A. V. S. De Reuck and M. O'Connor (Eds.) Ciba Foundation Symposium on Disorders of Language, London: J. \& A. Churchill Ltd.

Jakobson, R. (1968): Child Language, Aphasia and Phonological Universals. The Hague: Mouton.

Langacker, R. W. (1968): Language and Its Structure. Ncw York: Harcourt, Brace \& World, Inc.

Liberman, A. M., Cooper, F. S., Shankweiler, D. P. and Studdert-Kennedy, M. (1967): Perception of the spccch code. Psychological Review, 74, pp. 431461.

Marshall, J. C. and Newcombe, F. (1966): Syntactic and scmantic crors in paralexia. Neuropsychologica, 4, pp. 169-176.

McNeill, D. (1966): Developmental psycholinguistics. In F. Smith and G. Miller (Eds.), The Genesis of Languagc. Cambridgc: M.I.T. Press.

Menyuk, P. (1969): The Sentences Children Use. Cambridge: M.I.T. Press.

Rosenbaum, P. (1967): Specification and Utilisation of a Transformational Grammar. Scientific Report No. 2 of the IBM Corporation, New York.

Schlesinger, I. (1966): Sentence Structure and the Reading Process. The Hague: Mouton.

Weigl, E. and Bierwisch, M. (1970): Neuropsychology and Linguistics: Topics of common research. Foundations of language, 6 .

Whitaker, H. A. (1969): On the Represcntation of Language in the Human Brain. Working Papers, in Phonetics, No. 12. UCLA.

\section{Footnotes}

1. Hospital records show that he suffered a fracture of the middle fossa of the skull, but $I$ understand that this does not loeate the fracture vcry precisely. Beyond adding that he also had a right facial palsy, I am unfortunately unable to give a detailed medical diagnosis of the damage.

2. In more detail, the diagnosis was aphasia with severe reduction of language in all modalities, complicated by sensori-motor complications. I am indebted to $\mathrm{C}$. Kell for supplying me with this diagnosis. As will become clear later, there is strong evidence to question the diagnosis and indeed I do not find this disagreement surprising; doubtless, the Schuell test is confusing the aphasic impairment proper with the subject's bilingual inadequacies.

3. E. B. van Wyk has pointed out to me that this rule, as it stands, fails to reflect the'fact that the appearance of what I have termed the prothetic vowel of the noun prefix is not a purely phonological matter. The presence or absence of a prothetic vowel reflects a semantic contrast (and therefore a deep syntactic choice) between, respectively, definite or indefinite nouns preceding or following a positive or negative verb, and a quantificational meaning something like "any $X$ " where $X$ is a noun following a negative verb. This means that the presence or absence of a prothetic vowel in surface structure depends on certain deep syntactic features and the application (or not) of a segmentalising transformation; the final shape of this formative remains a phonological matter in Zulu. The rule for prothetic vowel spelling presented in the text therefore requires a modification to reflect the syntactic conditions under which it may apply. In its present form, the rule does not reflect these conditions.

4. It is interesting to notc that in the acquisition of their mother-tongue, Zulu children pass through a stage of development which exactly parallels W.N.'s non-alliterative concordial system.

5. In this discussion, I am not concerned to write a rule which will completely account for the observed errors. My point is rather to isolate the general form of the disturbance. 
6. W.N. actually shows more than just a breakdown of the alliterative concordial system. He is unable, for example, to produce sentences containing embedded constructions, succeeding after much perseveration only to produce a co-ordinated paraphrase of such sentences. Since this inability extends to right-branching structures as well, we could describe it more generally as a restriction on recursion in the grammar.

7. According to the Schuell diagnosis, W.N. would thus show a disturbance in competence in English, but according to my test his receptive modality is intact for Zulu. That is his Zulu competence is preserved.

\begin{abstract}
An attempt is made to explain certain expressive impairments in the speech of an Ndebele speaking aphasic in terms of a transformational grammar. The impairment is eventually located in a part of the lexicon, but owing to the standard view of linguistic competence, this explanation poses problems which at present resist resolution.
\end{abstract}

